\title{
Desenvolvimento e caracterização sensorial de Paçoca de Munguba (Pachira aquática
}

\author{
Aubl.) \\ Development and sensory characterization of Paçoca of Munguba (Pachira aquatic Aubl.) \\ Desarrollo y caracterización sensorial de Paçoca em Munguba (Pachira aquática Aubl.)
}

Recebido: 08/06/2021 | Revisado: 18/06/2021 | Aceito: 21/06/2021 | Publicado: 05/07/2021

\author{
Ana Karoline Bin Costa \\ ORCID: https://orcid.org/0000-0002-6623-6978 \\ Universidade Federal da Grande Dourados, Brasil \\ E-mail: anakaroline.engal@gmail.com \\ Ângela Dulce Cavenaghi Altemio \\ ORCID: https://orcid.org/0000-0002-3000-8869 \\ Universidade Federal da Grande Dourados, Brasil \\ E-mail: AngelaAltemio@ufgd.edu.br
}

\begin{abstract}
Resumo
O objetivo deste trabalho foi realizar uma pesquisa de mercado sobre consumo de paçoca de Munguba (Pachira aquatica Aubl.), além de elaborar formulações variando a adição de gordura animal e avaliar sensorialmente. Para a elaboração da paçoca, as sementes de Munguba foram secas em forno convencional e trituradas em multiprocessador. Neste estudo variou-se a porcentagem de manteiga, sendo o tratamento 1 (T1) sem adição, tratamento 2 (T2) com $2,83 \%$ e tratamento 3 (T3) com adição de 5,65\%. Realizou-se pesquisa de mercado sobre a Paçoca de amendoim e de Munguba (Pachira aquatica Aubl.). A análise sensorial foi realizada de forma virtual, e foram utilizados o teste de aceitação para os atributos cor e aparência, com julgadores não treinados, o teste de ordenação de preferência e uma pesquisa sobre o produto ideal, nos três tratamentos e na amostra comercial de amendoim. Na pesquisa de mercado foi possível notar que a paçoca do Munguba haveria aderência ao mercado. Pelo teste aceitação em relação a cor e aparência tiveram medias de escores entre 5 e 7, enquanto a comercial ficou entre 8 e 9. Em relação à comparação de paçoca ideal e as avaliações dadas as Paçocas de Munguba respectivamente no quesito cor teve boa aceitabilidade, porém em relação à textura aparente e granulometria aparente devem ser realizados novos estudos. Conclui-se que é possível elaborar paçoca do Munguba (Pachira aquatica Aubl.), no entanto é necessário melhorar a textura e conduzir testes sensoriais de sabor, textura e odor, pois foi feito somente análises visuais.
\end{abstract}

Palavras-chave: Aceitabilidade, Intenção de compra, Pesquisa de mercado.

\begin{abstract}
The objective of this work was to carry out a market research on the consumption of Munguba paçoca (Pachira aquatica $\mathrm{Aubl}$.), In addition to elaborating formulations varying the addition of animal fat and evaluating sensorially. To prepare the paçoca, the Munguba seeds were dried in a conventional oven and crushed in a multiprocessor. In this study, the percentage of butter varied, with treatment 1 (T1) without addition, treatment 2 (T2) with $2.83 \%$ and treatment 3 (T3) with addition of 5.65\%. Market research was carried out on Peanut and Munguba Paçoca (Pachira aquatica Aubl.). The sensory analysis was performed in a virtual way, and the acceptance test for the color and appearance attributes was used, with untrained judges, the preference ordering test and a search for the ideal product, in the three treatments and in the commercial sample of peanut. In the market research it was possible to notice that the Munguba paçoca would have adherence to the market. The acceptance test in relation to color and appearance had mean scores between 5 and 7, while the commercial was between 8 and 9. Regarding the comparison of the ideal paçoca and the evaluations given to the Paçocas de Munguba respectively in the item color, it had good acceptability in relation to texture apparent and granulometry apparent, further studies should be carried out. It is concluded that it is possible to prepare paçoca do Munguba (Pachira aquatica Aubl.), However it is necessary to improve the texture and conduct sensory tests of taste, texture and odor, as only visual analyzes were performed.
\end{abstract}

Keywords: Acceptability, Purchase intent, Market research.

\section{Resumen}

El objetivo de este trabajo fue realizar una investigación de mercado sobre el consumo de Munguba paçoca (Pachira aquatica Aubl.), Además de elaborar formulaciones variando la adición de grasa animal y evaluando sensorialmente. Para preparar la paçoca, las semillas de Munguba se secaron en un horno convencional y se trituraron en un multiprocesador. En este estudio varió el porcentaje de manteca, con tratamiento 1 (T1) sin adición, tratamiento 2 (T2) con 2,83\% y tratamiento 3 (T3) con adición de 5,65\%. La investigación de mercado se llevó a cabo en Peanut y 
Munguba Paçoca (Pachira aquatica Aubl.). El análisis sensorial se realizó de manera virtual, y se utilizó la prueba de aceptación de los atributos de color y apariencia, con jueces no capacitados, la prueba de orden de preferencia y una investigación del producto ideal, en los tres tratamientos y en la muestra comercial de maní. En la investigación de mercado se pudo notar que la paçoca Munguba tendría adherencia al mercado. La prueba de aceptación en relación al color y apariencia tuvo puntuaciones medias entre 5 y 7 , mientras que la comercial estuvo entre 8 y 9 . En cuanto a la comparación de la paçoca ideal y las evaluaciones dadas a Paçocas de Munguba respectivamente en el ítem color, tuvo buena aceptabilidad, sin embargo, en relación con la textura aparente y la granulometria aparente, se deben realizar más estudios. Se concluye que es posible preparar paçoca do Munguba (Pachira aquatica Aubl.), Sin embargo es necesario mejorar la textura y realizar pruebas sensoriales de sabor, textura y olor, ya que solo se realizaron análisis visuales.

Palabras clave: Aceptabilidad, Intención de compra, Investigación de mercado.

\section{Introdução}

Munguba cujo nome cientifico é (Pachira aquatica Aubl.), pertence à família Malvaceae ou Bombacaceae, nativa do sul do México até o norte da América do Sul. Munguba é uma árvore que se adapta em ambientes úmidos e com muita exposição de luz, se trata de uma árvore que se encontra a margens de rios e lagos (Peixoto \& Escudeiro, 2002). No interior do fruto existem sementes que possui amêndoas ricas em óleo e possui uma porcentagem relevante, sendo o teor lipídico de 46,62\%, o proteico de 13,75\% e na forma de torta apresentou um índice de 28,27\% de proteínas (Silva, Azevedo \& Azevedo, 2015). Sua humidade quando tostada é de 3,26\% e sua fibra de 19,72\% (Silva, Morais, Costa, Teles, Rodrigues, Santos, Nascimento, Cantanhede Filha \& Pires, 2020).

Segundo Lorenzi (1992), a Pachira aquática Aublet foi introduzida em arborização urbana na segunda metade do século XIX pelo botânico e paisagista francês Glaziou. Nos estados de São Paulo e Rio de Janeiro se expandiu graças aos trabalhos paisagísticos de Roberto Burle Marx na década de 60. É uma árvore de rápido crescimento e nas condições edafoclimáticas apresenta porte médio (Jorge \& Luzia, 2012).

Por ser uma árvore frondosa é amplamente utilizada na arborização de cidades do interior do país, e atrai atenção por suas flores exóticas. No México, infusões das cascas de Pachira aquatica são empregadas pela medicina popular no tratamento de diabetes (Andrade-Cetto \& Heinrich, 2005).

No Mato do Grosso do Sul, a árvore de Munguba (Pachira aquatica Aubl.) é frequentemente encontrado pelas ruas de suas cidades. Grande parte das pessoas que o cultivam não tem o conhecimento de que o fruto contido na arvore é comestível, sendo assim, grande parte desse fruto, no estado, é perdido devido à falta de informação.

A paçoca é um doce brasileiro, típico da região Sudeste, feito à base de amendoim torrado, moído e prensado, sendo relatado como um produto de alta aceitabilidade (Wang, Cabral \& Borges, 1999). Além do amendoim, outros ingredientes, como farinha de trigo, fubá, açúcar, mel e gordura participam em maiores ou menores proporções. O processamento para obtenção de paçoca é descrito por Wang et al. (1999) e Ribeiro (2006) como uma homogeneização dos ingredientes, com o amendoim torrado e moído atuando como base das formulações, com posterior moldagem e prensagem.

Além disso, o Munguba (Pachira aquatica Aubl.) ao ser torrado tem sabor característico muito semelhante ao amendoim.

Desta maneira objetivou-se realizar uma pesquisa de mercado sobre consumo de paçoca de Munguba (Pachira aquatica Aubl.), além de elaborar formulações variando a adição de manteiga para verificar sua influência na textura e avaliar sensorialmente os atributos visuais de cor e aparência. 


\section{Metodologia}

Os Mungubas (Pachira aquática Aubl.) foram coletados na cidade de Dourados - MS, quando o fruto estava maduro. Neste estágio as sementes foram retiradas do fruto, conforme Figura 1 e armazenadas em sacos plásticos sob-refrigeração a $23^{\circ} \mathrm{C}$. Os demais ingredientes para a elaboração da paçoca foram adquiridos no mercado local.

Para este estudo foram realizados três tratamentos, onde variou-se a quantidade de manteiga de acordo com as formulações e adquirido amostra comercial de paçoca de amendoim para fazer a comparação.

O produto foi elaborado e então feitos vídeos e fotos para conduzir a avaliação sensorial de forma virtual utilizando a plataforma Google Forms®.

Figura 1 - Semente de Munguba (Pachira aquática Aubl.) com casca.

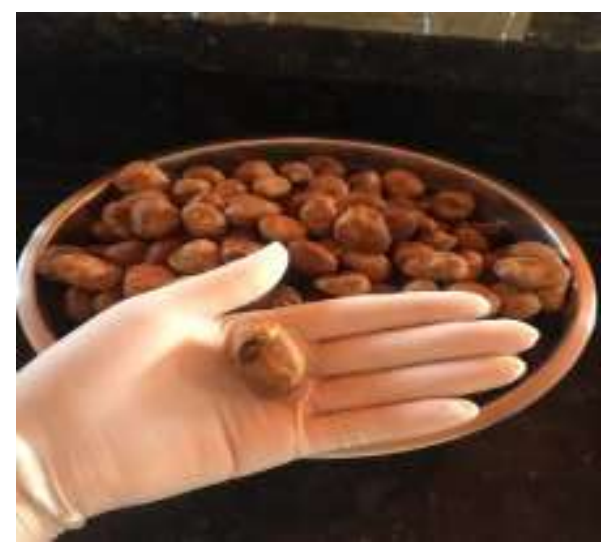

Fonte: Autores.

Para a elaboração da Paçoca de Munguba (Pachira aquática Aubl.), as sementes foram descongeladas e retiradas as cascas, conforme apresentado na Figura 2a, pode-se observar que elas possuem textura parecida com cogumelo. Em seguidas foram secas em forno convencional por 40 minutos à $180^{\circ} \mathrm{C}$ e ficaram conforme apresentado na Figura 2 b. Após a secagem foram trituradas em multiprocessador, Walita Master Plus, até atingir granulometria aparentemente fina, conforme apresentado na Figura 2 c.

Figura 2 - Semente de Munguba (Pachira aquática Aubl.) sem casca (a), após a secagem (b), após trituração (c).
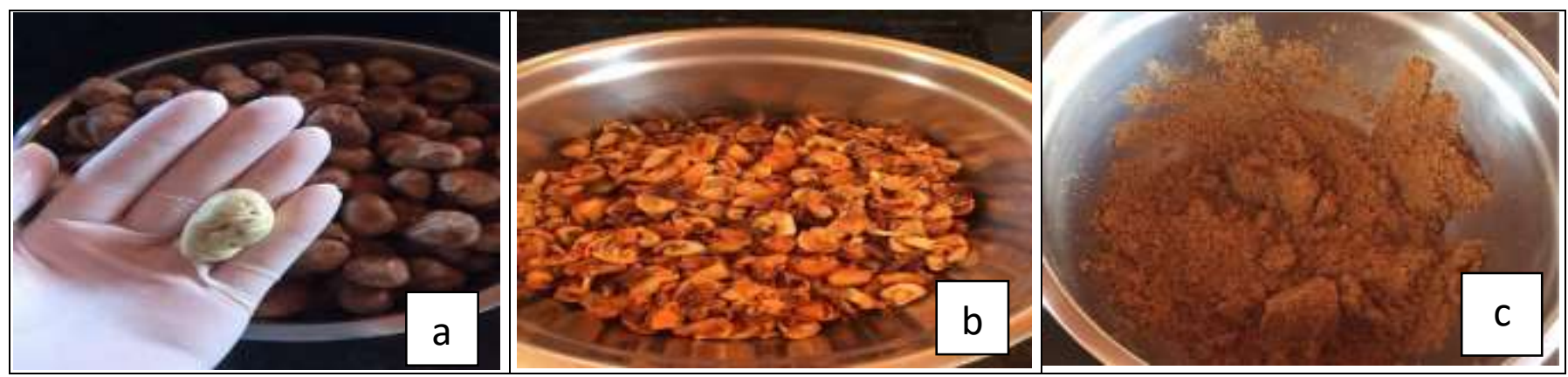

Fonte: Autores.

Para este estudo elaborou-se três tratamentos e as formulações das paçocas utilizando farinha de Munguba (Pachira aquática Aubl.) encontram-se na Tabela 1. 
Tabela 1 - Formulações dos tratamentos de Paçoca elaborados com farinha de Munguba (Pachira aquática Aubl.).

\begin{tabular}{lccc}
\hline \multicolumn{1}{c}{ Ingredientes } & T1 (\%) & T2 (\%) & T3 (\%) \\
\hline Farinha de Munguba & 49,50 & 49,50 & 49,50 \\
Água & 29,65 & 29,65 & 29,65 \\
Açúcar & 20,00 & 20,00 & 20,00 \\
Sal refinado & 0,85 & 0,85 & 0,85 \\
Manteiga & 0,00 & 2,83 & 5,65 \\
\hline
\end{tabular}

T1: Paçoca de Munguba sem adição de manteiga, T2: Paçoca de Munguba com adição de 2,83\% de manteiga e T3: Paçoca de Munguba com adição de 5,65\% de manteiga. Fonte: Autores.

Para elaboração das paçocas a farinha de Munguba (Pachira aquática Aubl.) as quantidades dos ingredientes seguiram a Tabela 1. O preparo da paçoca a farinha de Munguba foi misturada ao sal e em seguida adicionada uma calda onde a água e o açúcar de cada formulação foi feito levada ao fogo médio com agitação constante até ficar visualmente espessa. Após a adição da calda continuou-se a homogeneização até atingir a liga desejada. Nos tratamentos 2 e 3 foi adicionado manteiga, conforme pode ser observado na Tabela 1, para verificar a diferenciação na textura aparente da paçoca. Em seguida esta mistura foi enformada ficando em descanso até atingir temperatura ambiente, e então cortadas com arestas de 2,0 por 2,5 cm, seguindo os parâmetros da amostra comerciais de Paçoca de Amendoim, conforme apresentado na Figura 3.

Figura 3 - Paçoca de Munguba sem adição de manteiga (a), Paçoca de Munguba com adição de 2,83\% de manteiga (b), Paçoca de Munguba com adição de 5,65\% de manteiga (c) e Paçoca de amendoim (amostra comercial) (d).
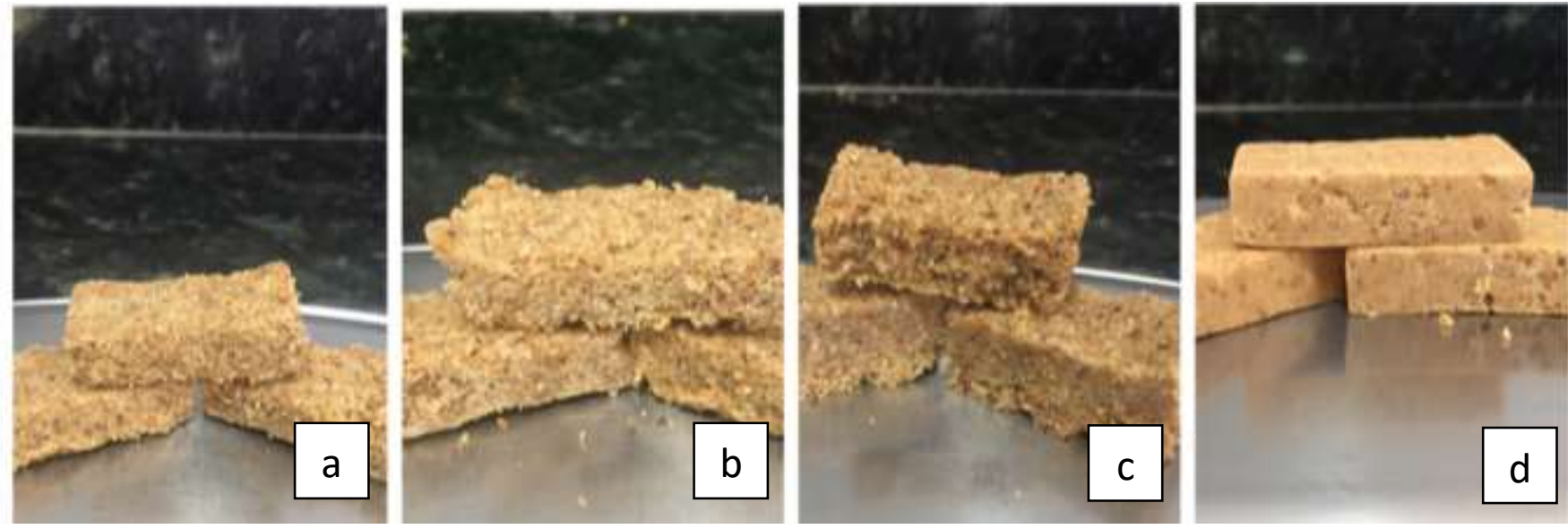

Fonte: Autores.

\subsection{Pesquisa de Mercado}

A coleta de dados pelo Formulário da pesquisa de mercado ocorreu através da plataforma Google Forms®, no qual foi respondido por 102 pessoas. O mesmo foi divulgado via Whatsapp®, Facebook ${ }^{\circledR}$ e outras plataformas de redes sociais. A pesquisa de mercado foi realizada por Pesquisa Exploratória, metodologia adaptada de Demo (1995).

As perguntas feitas na pesquisa de mercado foram o e-mail do entrevistado, gênero, faixa etária e estado em que reside, possui alergia a amendoim, consome paçoca, a frequência do consumo de paçoca, se ele conhecia o fruto do Munguba ou já comeu e que se o produto tivesse um sabor característico muito parecido com paçoca, se o entrevistado consumiria. Em relação ao seu valor de mercado, os entrevistados foram indagados em relação à intenção de compra. 


\subsection{Análise sensorial}

A avaliação sensorial foi feita de forma virtual através da plataforma Google Forms® com 114 julgadores não treinados. Primeiramente os entrevistados deveriam selecionar termos descritores que descrevessem a paçoca ideal, e em seguida foram apresentados vídeos da paçoca de amendoim (comercial) e dos tratamentos elaborados com farinha de Munguba (Pachira aquática Aubl), codificadas com três dígitos ao acaso aos julgadores.

Os termos descritores foram levantados por cinco julgadores pelo método tradicional que consiste em uma reunião onde cada julgador fala termos que representa aquela amostra e o produto ideal. Os termos levantados foram para o produto ideal foram textura firme, textura esfarelenta, textura moderadamente esfarelenta, textura moderadamente macia, muito doce, moderadamente doce, pouco doce, levemente salgada, moderadamente salgada, salgada, cor característica de paçoca, odor característico de paçoca, granulometria fina, granulometria média e granulometria grossa. Para as amostras foram levantados os termos cor semelhante a paçoca de amendoim, cor moderadamente semelhante a paçoca de amendoim, aparência pouco semelhante a paçoca de amendoim, aparência semelhante a paçoca de amendoim, aparência moderadamente semelhante a paçoca de amendoim, textura aparente macia, textura aparente esfarelenta, textura aparente dura, textura aparente moderadamente dura, textura aparente moderadamente esfarelenta, textura aparente moderadamente dura, granulometria aparente fina, granulometria aparente media e granulometria aparente grossa.

Para a avaliação dos atributos cor aparente e aparência da Paçoca de Munguba (Pachira aquática Aubl) e da comercial foi aplicado o teste de aceitação utilizando-se escala hedônica estruturada de 9 pontos, onde $9=$ gostei muitíssimo à $1=$ desgostei muitíssimo, adaptada da metodologia de Meilgaard, Civille e Carr (1999). As amostras de cada tratamento foram cortadas 2 por $2,5 \mathrm{~cm}$, codificadas ao acaso com números de três dígitos e fotografadas. Os resultados do experimento foram tratados estaticamente através da análise de variância (ANOVA) e as médias comparadas pelo teste de Tukey ao nível de 5\% de significância, utilizando o software SISVAR.

Também foi solicitado que respondessem sobre sua intenção de compra, utilizando escala de 5 pontos, onde $5=$ certamente compraria à $1=$ certamente não compraria. Os resultados foram expressos em porcentagem de intenção de compra.

Ao final foi aplicado o teste de ordenação de preferência, sendo apresentado fotos dos produtos e solicitado aos julgadores que ordenasse da menos preferido (1) a mais preferida (4). A análise dos resultados utilizou o método de Friedman (Newell \& MacFarlane, 1987), ao nível de 5\% de significância.

\section{Resultados e Discussão}

\subsection{Pesquisa de Mercado}

A Figura 4 apresenta o gênero dos entrevistados que responderam à pesquisa de mercado sobre consumo de paçoca de amendoim e Munguba (Pachira aquática Aubl) e a faixa etária dos entrevistados. 
Figura 4 - Percentual do gênero (A) e faixa etária (B) dos entrevistados que responderam à pesquisa de mercado sobre consumo de paçoca de amendoim e Munguba (Pachira aquática Aubl).

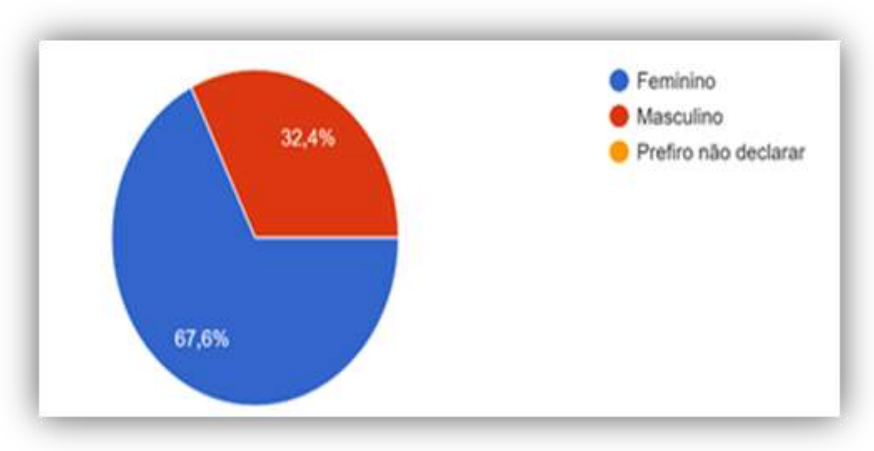

(A)

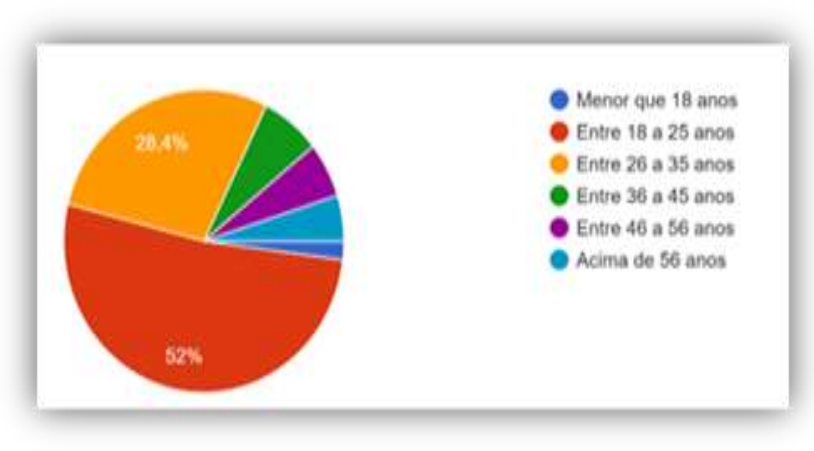

(B)

Fonte: Autoria própria através do formulário Google Forms®.

Observa-se na Figura 4 (A) que 67,6\% dos entrevistados eram mulheres e 32,4\% eram homens e que maior faixa etária Figura 4 (B) foi com a idade entre 18 a 25 anos sendo 52\% dos participantes, seguido por 28,4\% entre 26 a 35 anos, $6,9 \%$ entre 36 a 45 anos, 5,9\% entre 46 a 56 anos, 4,9\% acima de 56 anos e $2 \%$ menor que 18 anos.

A Figura 5 apresentam respectivamente as respostas relativas à pergunta se consomem paçoca de amendoim (A) e a qual a frequência de consumo (B).

Figura 5 - Porcentuais em relação consumo (A) e a frequência de consumo (B) de paçoca de amendoim.

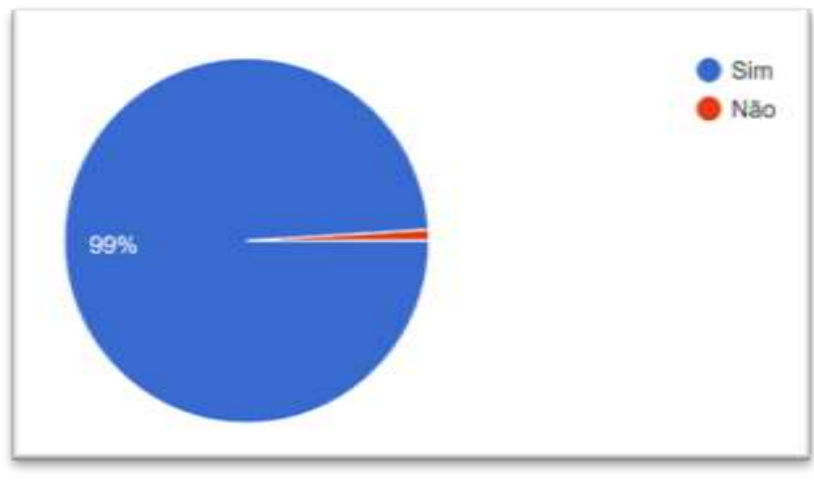

(A)

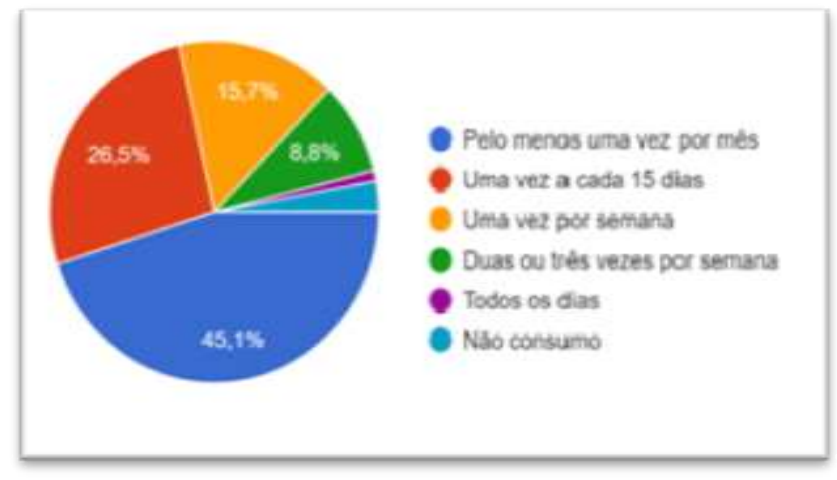

(B)

Fonte: Autoria própria através do formulário Google Forms®.

Observa-se na Figura 5 (A) que grande parte dos entrevistados, sendo 99\% fazem o consumo de paçoca de amendoim. De acordo com as respostas obtidas na Figura 5 (B) 45,1\% consomem paçoca pelo menos uma vez por mês, 26,5\% consome uma vez a cada quinze dias, $15,7 \%$ uma vez por semana e 8,8\% consome duas ou três vezes por semana.

A Figura 6 apresenta o resultado em porcentagem em relação ao conhecimento do entrevistado do fruto Munguba (Pachira aquática Aubl.), se já tinha comido ou se comeria o Munguba. 
Figura 6 - Valores percentuais apresentados ao conhecimento e consumo do Munguba.

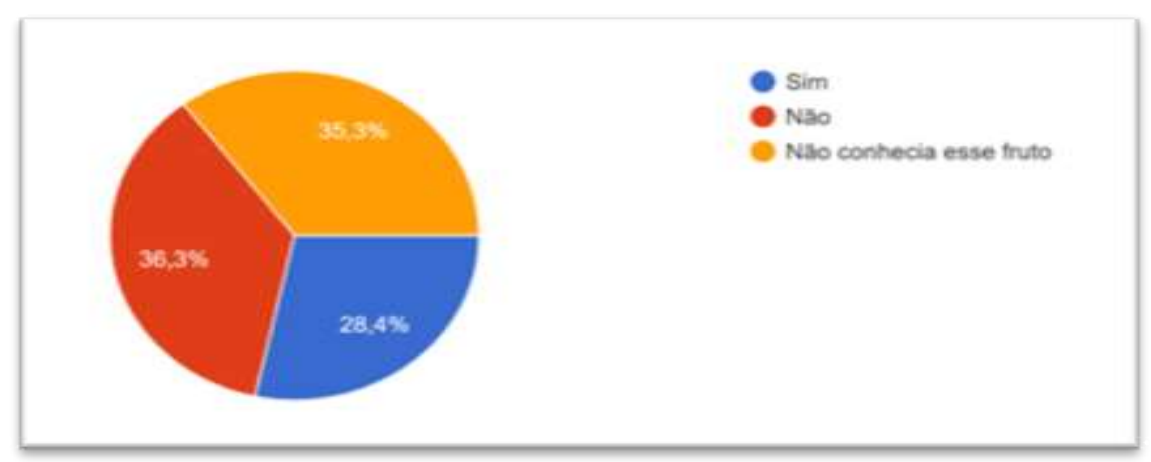

Fonte: Autoria própria através do formulário Google Forms®.

Percebe-se na Figura 6 que 36,3\% não consumiram o fruto, 35,3\% não conhecem o fruto e 28,4\% já consumiram o Munguba (Pachira aquática Aubl.).

Na Figura 7 (A) questiona ao entrevistado caso a Paçoca de Munguba tivesse sabor semelhante ao de amendoim, se haveria interesse de consumir e na (B) considerando que o valor da Paçoca de Munguba não fosse problema, se haveria intenção de compra.

Figura 7 - Valores percentuais apresentados ao interesse de consumo da paçoca de Munguba (Pachira Aquática Aubl.) (A) e intenção de compra da Paçoca de Munguba (B).

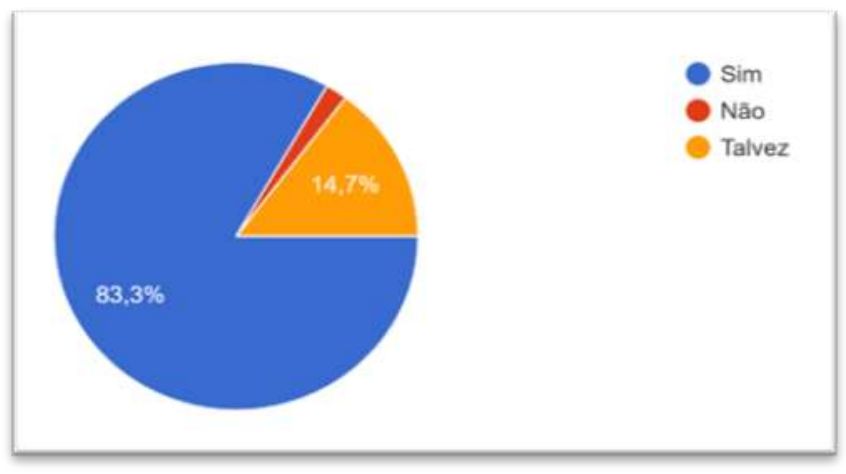

(A)

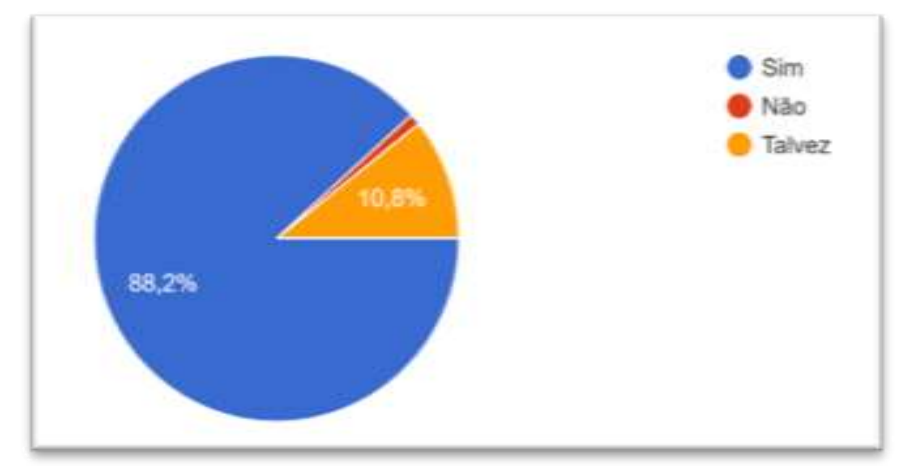

(B)

Fonte: Autoria própria através do formulário Google Forms ${ }^{\circledR}$.

Notou-se na Figura 7 (A) que 83,3\% dos entrevistados consumiriam a Paçoca de Munguba (Pachira aquática $A u b l$.) se soubesse que o sabor seria semelhante com o de paçoca de amendoim, 14,7\% talvez consumiriam a Paçoca de Munguba e 2\% não consumiriam. Já na Figura 7 (B) 88,2\% comprariam a Paçoca de Munguba, 10,80\% talvez compraria e $1 \%$ não compraria.

\subsection{Análise sensorial}

A Figura 8 apresenta a caracterização do produto ideal utilizando os termos descritores levantados pelo teste tradicional para paçoca. 
Figura 8 - Termos descritores levantados elencados pelos participantes em relação ao que consideram ideal em uma paçoca.

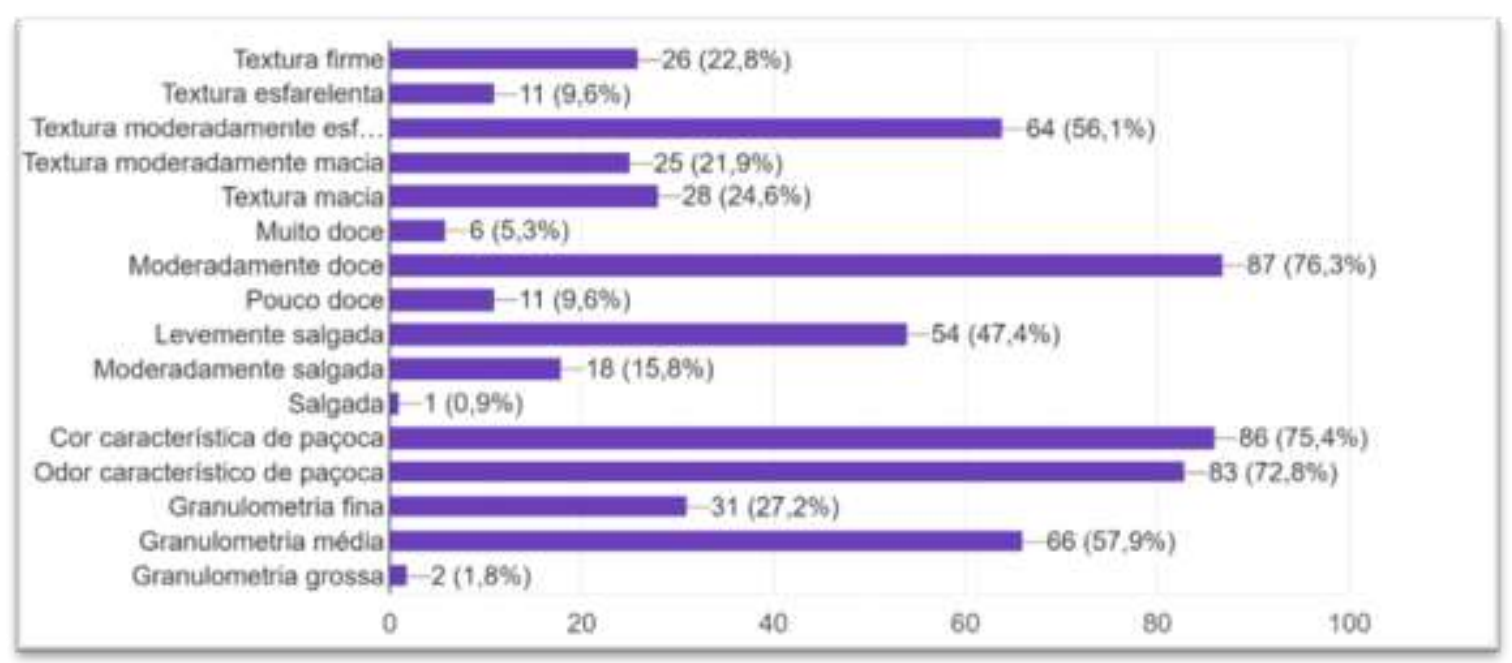

Fonte: Autoria própria através do formulário Google Forms®.

Observa-se na Figura 8 que para grande parte dos entrevistados as características mais importantes para a paçoca ideal em relação ao atributo textura foi "textura moderadamente esfarelenta" com 56,1 \% Para o atributo sabor, "moderadamente doce" com 76,3\% e "levemente salgada" com 47,4\% apresentaram maior quantidade de escolhas. Para cor apresentam maiores porcentagens "cor característica de paçoca" com 75,4\% e para odor 72,8\% escolheram "odor característico de paçoca". No atributo granulometria, "granulometria média" apresentou maior quantidade de escolhas com $57,9 \%$.

Na Figura 9 são mostrados os valores com relação à atribuição de características para a amostra comercial.

Figura 9. Características atribuídas a amostra comercial.

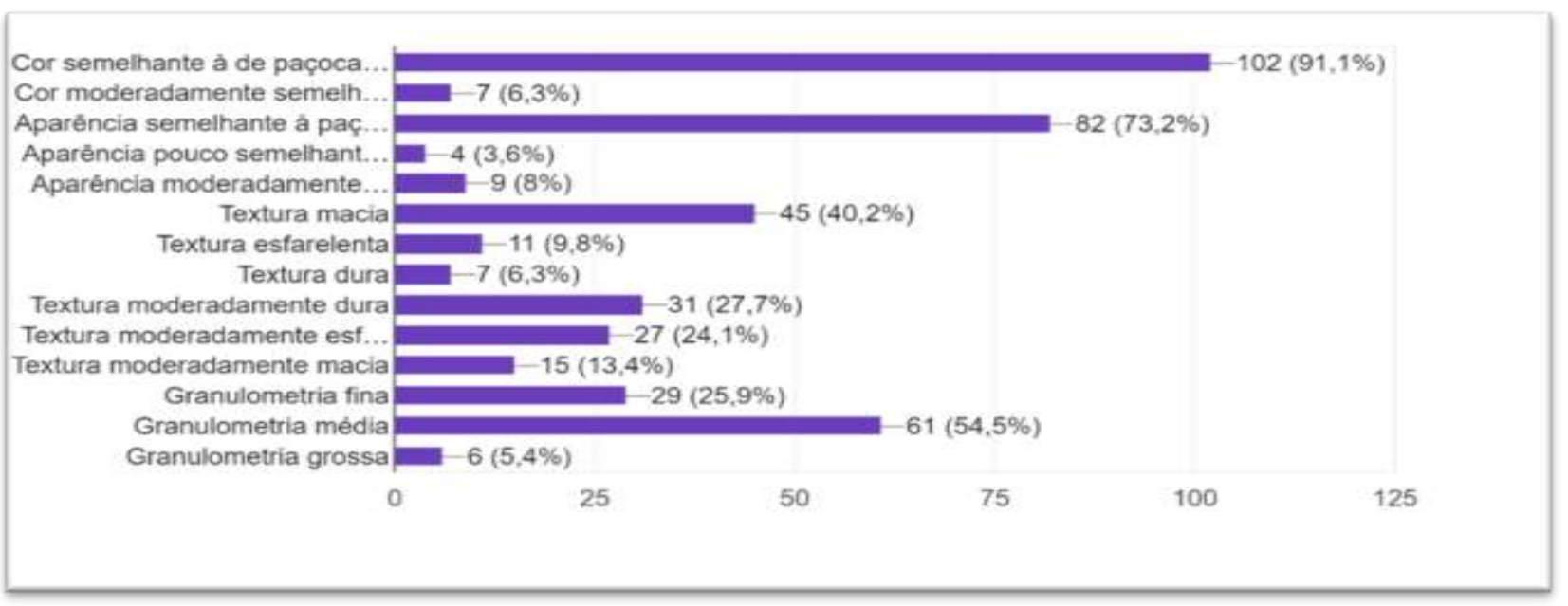

Fonte: Autoria própria através do formulário Google Forms®.

Para a amostra comercial a característica cor aparente atribuída na Figura 9 apresentou 91,1\% de escolhas para "cor semelhante à de paçoca de amendoim". Para o atributo aparência, houveram 73,3\% de escolhas para "aparência semelhante à paçoca de amendoim". Em textura aparente, apresentou-se maior quantidade de escolhas "textura macia" com 40,2\%. Para o atributo granulometria aparente houveram 54,5\% de escolhas para "granulometria média". 
Em Figura 10 observa-se as características atribuídas ao tratamento 1 Paçoca de Munguba (Pachira aquática Aubl.) sem adição de manteiga.

Figura 10. Características atribuídas a Paçoca de Munguba (Pachira aquática Aubl.) sem adição de manteiga.

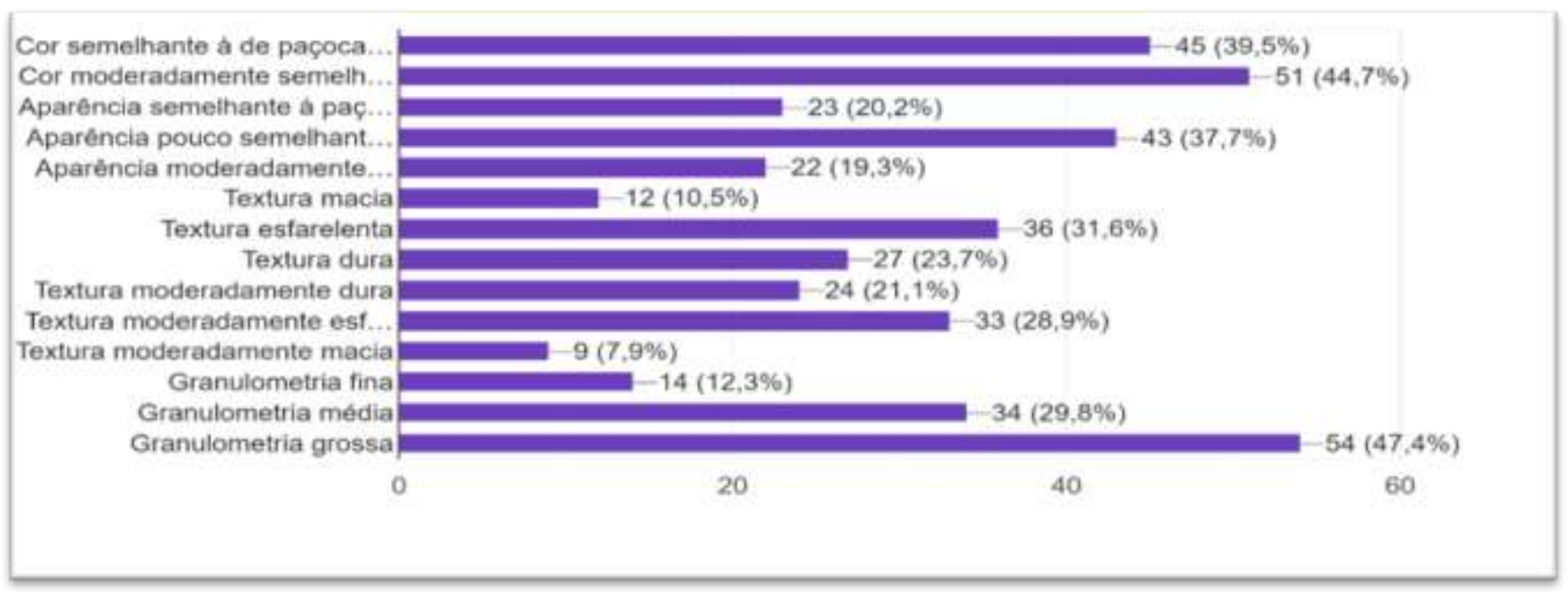

Fonte: Autoria própria através do formulário Google Forms ${ }^{\circledR}$.

Foi possível notar na Figura 10 que para o atributo cor aparente, obteve maior quantidade de escolhas "cor moderadamente semelhante à cor de paçoca" com 44,7\%. Para aparência com 37,7\% de escolhas "aparência pouco semelhante à paçoca de amendoim" foi a mais escolhida, em seguida, no atributo textura aparente para Paçoca de Munguba sem adição de manteiga, a mais escolhido foi "textura esfarelenta" com 31,6\%. Para granulometria aparente 47,4\% escolheram "granulometria grossa” para caracterizar a Paçoca de Munguba sem adição de manteiga.

A Figura 11 demonstra as características mais marcadas pelos entrevistados com relação ao tratamento 2 Paçoca de Munguba com adição de $2,83 \%$ de manteiga.

Figura 11. Características atribuídas a Paçoca de Munguba (Pachira aquatica Aubl.) com adição de 2,83\% de manteiga.

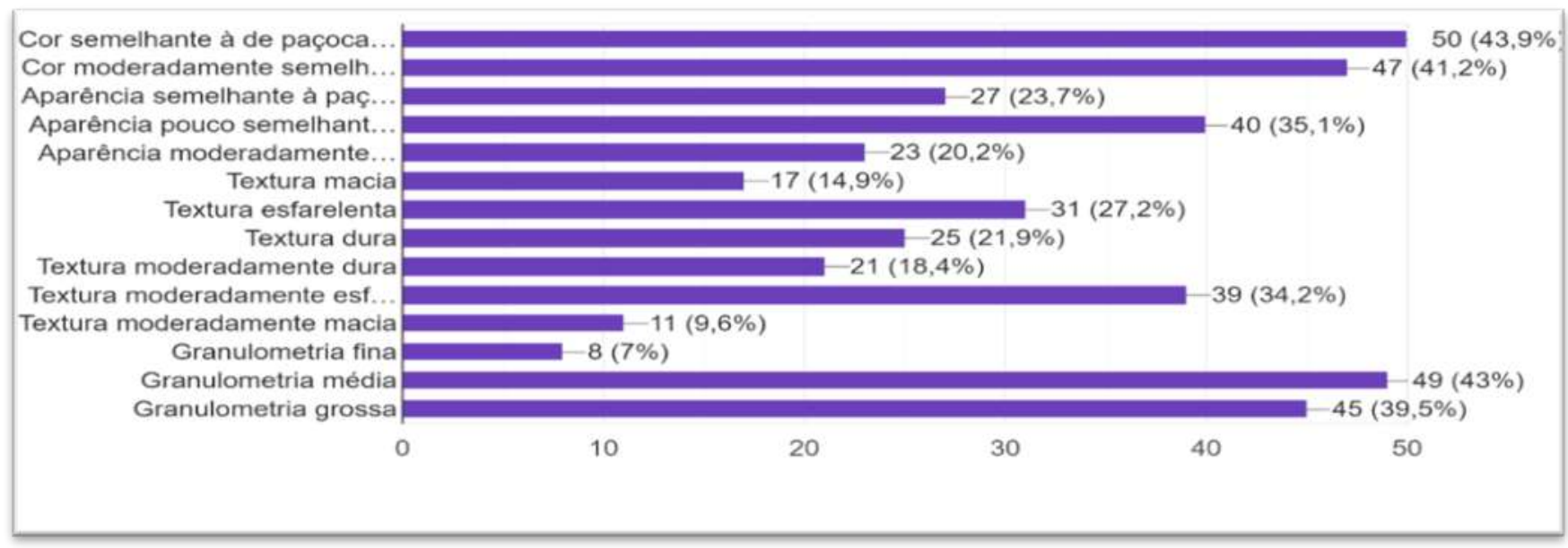

Fonte: Autoria própria através do formulário Google Forms ${ }^{\circledR}$.

É possível verificar na Figura 11 para Paçoca de Munguba com adição de 2,83\% de manteiga no atributo cor aparente que apresentou 43,9\% de escolhas para "cor semelhante à de paçoca de amendoim”. Para o atributo aparência, houveram 
35,1\% para "aparência pouco semelhante a paçoca de amendoim" sendo a mais escolhida. Em textura aparente, apresentou-se maior quantidade de escolhas "textura moderadamente esfarelenta" com 34,2\%. Para o atributo granulometria aparente houve $43 \%$ de escolhas para "granulometria média".

Na Figura 12 é possível analisar as características marcadas pelos provadores para o tratamento 3 Paçoca de Munguba com adição de $5,65 \%$ de manteiga.

Figura 12. Características atribuídas a Paçoca de Munguba (Pachira aquatica Aubl.) com adição de 5,65\% de manteiga.

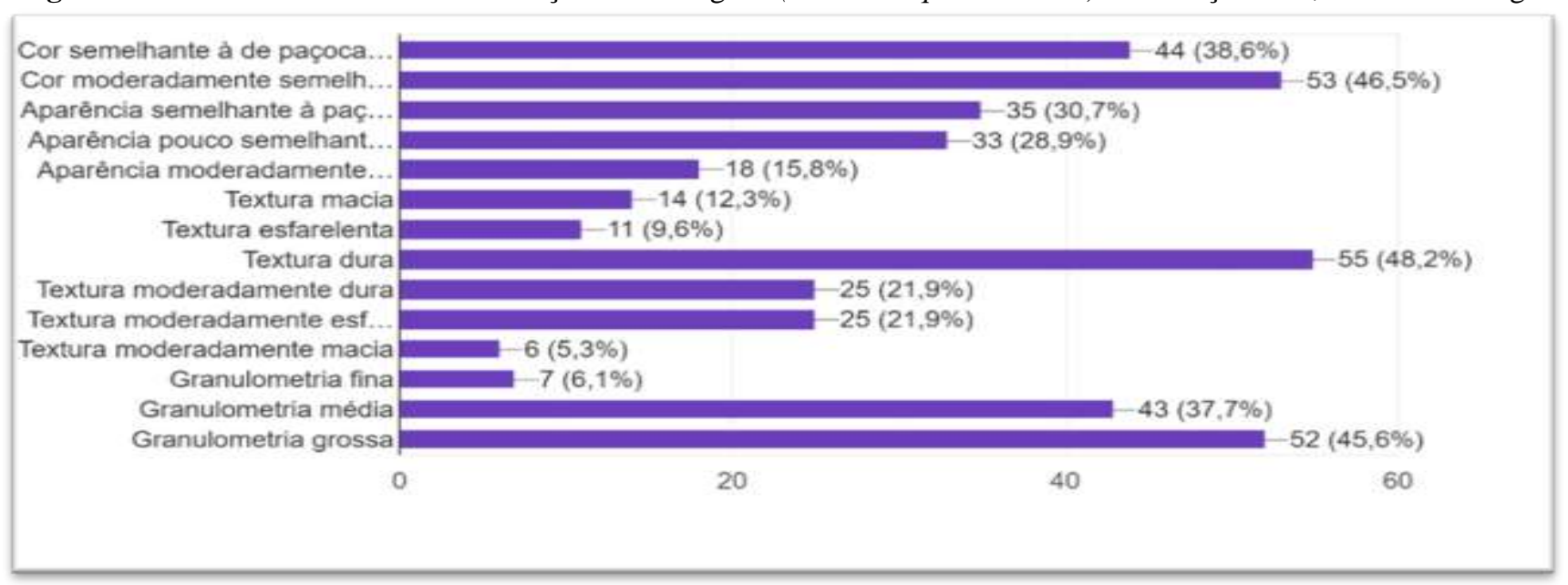

Fonte: Autoria própria através do formulário Google Forms®.

Considerou-se a partir da Figura 12 para Paçoca de Munguba com adição de 5,65\% de manteiga para cor obteve 46,5\% de escolhas para "cor moderadamente semelhante à paçoca de amendoim". Para o atributo aparência o mais escolhido foi “aparência semelhante à paçoca de amendoim” com 30,7\% de escolhas. Em textura aparente para Paçoca de Munguba com adição de 5,65\% de manteiga, o mais escolhido com 48,2\% foi "textura dura". No atributo granulometria aparente, 45,6\% escolheram "granulometria grossa".

A Tabela 2 apresenta os valores médios dos escores dos atributos sensoriais cor aparente e aparência pelo teste de aceitação para a Paçoca de Munguba (Pachira aquática Aubl.) sem adição de manteiga, Paçoca de Munguba com adição de 2,83\% de manteiga, Paçoca de Munguba com adição de 5,65\% de manteiga e de Paçoca de amendoim (amostra comercial).

Tabela 2 - Teste de aceitação para os atributos sensoriais de cor aparente e aparência de Paçoca de Munguba (Pachira aquática Aubl.) sem adição de manteiga, Paçoca de Munguba com adição de 2,83\% de manteiga, Paçoca de Munguba com adição de 5,65\% de manteiga e de Paçoca de amendoim (amostra comercial).

\begin{tabular}{ccc}
\hline Amostras & Cor & Aparência \\
\hline Co & $8,10^{\mathrm{a}} \pm 1,38$ & $8,22^{\mathrm{a}} \pm 1,40$ \\
T1 & $6,98^{\mathrm{b}} \pm 1,99$ & $6,17^{\mathrm{b}} \pm 2,13$ \\
T2 & $6,42^{\mathrm{b}} \pm 2,10$ & $5,39^{\mathrm{c}} \pm 2,36$ \\
T3 & $6,64^{\mathrm{b}} \pm 2,20$ & $6,15^{\mathrm{b}} \pm 2,36$
\end{tabular}

Co: Paçoca de amendoim (Amostra comercial); T1: Paçoca de Munguba sem adição de manteiga; T2: Paçoca de Munguba com adição de 2,83\% de manteiga; T3: Paçoca de Munguba com adição de 5,65\% de manteiga. Letras diferentes na mesma coluna diferem significativamente entre si, pelo teste de Tukey, ao nível de significância de $5 \%$. Fonte: Autores. 
Pela Tabela 2 nota-se que a paçoca de amendoim (amostra comercial) obteve médias de escores que variaram entre "gostei muito" e "gostei muitíssimo" para os atributos cor e aparência. As médias dos escores da paçoca de farinha de Munguba (Pachira aquática Aubl.) variaram de "gostei ligeiramente" a "gostei moderadamente" para o atributo cor e de "nem gostei e nem desgostei" a "gostei ligeiramente" para o atributo aparência.

Em relação ao atributo cor (Tabela 2) houve diferença significativa $(p<0,05)$ entre a paçoca de amendoim com as demais amostras, que não diferiram entre si $(\mathrm{p} \geq 0,05)$. E para o atributo aparência as amostras T1 e T3 não diferiram entre si $(p \geq 0,05)$ e ambas diferiram das demais $(p<0,05)$, que diferiram $(p<0,05)$ entre si, conforme pode-se observar na Tabela 2.

Soares, Santiago, Campos, Carmo e Guerra (2015) em sua análise sensorial de paçoca de cumbaru com adição de farinha de soja e linhaça em diferentes percentuais o qual foi aplicado teste de aceitação para 60 provadores, foram obtidas as médias de notas das três formulações feitas, a cor obteve 7,92 e a aparência 8,02 obtendo diferença significativa nas amostras. Para Lima, Garruti, Araujo e Garcia (2015) que elaborou paçoca com amêndoa de castanha de caju apresentou aceitação, com valor hedônico médio de 7,3, que corresponde, na escala hedônica, a avaliações entre "gostei" e "gostei muito". Valores inferiores foram encontrados para Ribeiro (2006) para paçoca elaborada com resíduo da extração do leite de soja, que apresentou valores para aceitação sensorial global variando de 5,0 a 6,5 (escala de 9 pontos).

A Figura 13 apresenta a intenção de compra da Paçoca de Munguba (Pachira aquática Aubl.) sem adição de manteiga, Paçoca de Munguba com adição de 2,83\% de manteiga, Paçoca de Munguba com adição de 5,65\% de manteiga e de Paçoca de amendoim (amostra comercial).

Figura 13. Intenção de compra da Paçoca de Munguba (Pachira aquática Aubl.) sem adição de manteiga, Paçoca de Munguba com adição de 2,83\% de manteiga, Paçoca de Munguba com adição de 5,65\% de manteiga e de Paçoca de amendoim (amostra comercial).

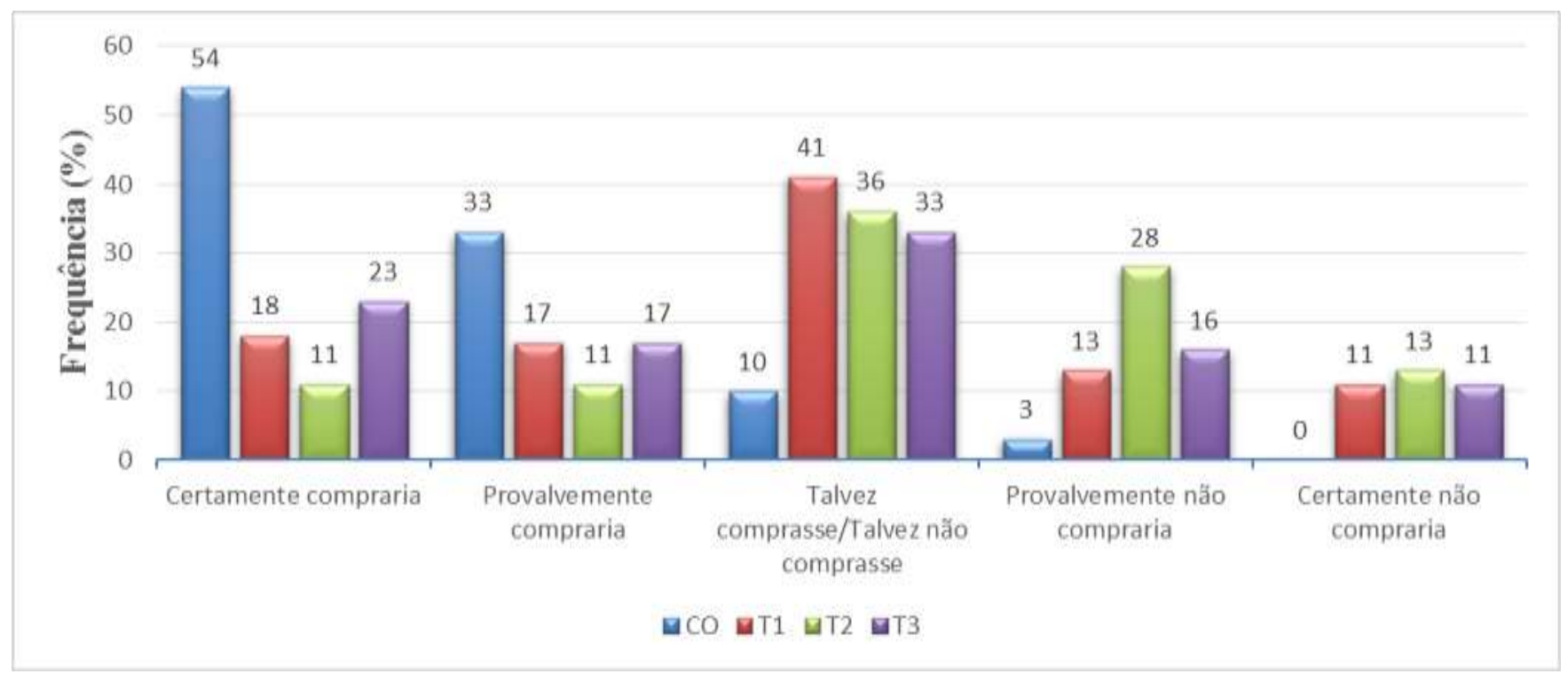

Co: Paçoca de amendoim (Amostra comercial); T1: Paçoca de Munguba sem adição de manteiga; T2: Paçoca de Munguba com adição de 2,83\% de manteiga; T3:Paçoca de Munguba com adição de 5, 65\% de manteiga. Fonte: Autores.

Pode-se observar pela Figura 13 que o somatório das intenções de compra de certamente com provavelmente comprariam para a amostra comercial foi de 77\%, para T1 Paçoca de Munguba sem adição de manteiga foi de $35 \%$, para T2 Paçoca de Munguba com adição de 2,83\% de manteiga foi de $22 \%$ e T3 Paçoca de Munguba com adição de 5,65\% de manteiga foi de $40 \%$, com estes valores conclui-se que as paçocas elaboradas com farinha de Munguba (Pachira aquática $A u b l$.) tiveram valores bem abaixo de intenção de compra, e dentro delas a T2 obteve o menor valor. Ao considerar os valores 
dos indecisos (Figura 13), os tratamentos T1 e T3 teriam intenção de compra acima de 70\%, que poderia alcançar este público com alteração do produto em relação a textura e com análise sensorial de sabor e odor.

Pela somatória das intenções de provavelmente não compararia e certamente não compraria observa-se na Figura 13 valores que variaram de entre $23 \%$ no $\mathrm{T} 1$ a $41 \%$ para T2, comprovando que as formulações devem ser modificadas para aumentar a intenção de compra e este serem comercializados.

$\mathrm{Na}$ Tabela 3 demonstra o resultado referente ao teste de preferência das amostras de Paçoca de Munguba (Pachira aquática Aubl.) sem adição de manteiga, Paçoca de Munguba com adição de 2,83\% de manteiga, Paçoca de Munguba com adição de 5,65\% de manteiga e de Paçoca de amendoim (amostra comercial).

Tabela 3. Teste de ordenação de preferência para Paçoca de Munguba (Pachira aquática Aubl.) sem adição de manteiga, Paçoca de Munguba com adição de 2,83\% de manteiga, Paçoca de Munguba com adição de 5,65\% de manteiga e de Paçoca de amendoim (amostra comercial).

Amostras Somatório das ordenações de preferência

$\begin{array}{lc}\text { Co } & 292^{\mathrm{a}} \\ \text { T1 } & 301^{\mathrm{a}} \\ \text { T2 } & 249^{\mathrm{b}} \\ \text { T3 } & 298^{\mathrm{a}}\end{array}$

Co: Paçoca de amendoim (Amostra comercial); T1: Paçoca de Munguba sem adição de manteiga; T2: Paçoca de Munguba com adição de 2,83\% de manteiga; T3: Paçoca de Munguba com adição de 5,65\% de manteiga. Letras diferentes na mesma coluna diferem significativamente entre si, pelo método de Friedman, ao nível de significância de $5 \%$. Fonte: Autoria própria através do formulário Google Forms®.

Com base na Tabela 3 é possível observar que em relação à preferência dos julgadores, não houve diferença significativa entre a amostra comercial, T1 e T3, porém a amostra T2 diferiu significativamente das amostras T1, T2 e da amostra comercial $(p<0,05)$, o que corrobora a intenção de compra quando se faz o somatório das intenções de certamente com provavelmente compraria com talvez comprasse e talvez não comprasse.

\section{Conclusão}

Com relação à pesquisa de mercado demonstrou que o produto pode ter boa aderência na indústria de alimentos devido à alta quantidade de pessoas que considerariam a compra do produto caso dinheiro não fosse um problema em questão.

Para o produto ideal em relação aos atributos mais escolhidos foram "textura moderadamente esfarelenta", "moderadamente doce", "cor característica de paçoca", "odor característico de paçoca" e "granulometria média". Em comparação com a paçoca de amendoim ideal, o tratamento 1 de Paçoca de Munguba sem adição de manteiga, a textura aparente se assemelhou, no tratamento 2 de Paçoca de Munguba com adição de 2,83\% de manteiga em relação a paçoca de amendoim ideal a granulometria média foram as mais escolhidas para este atributo e para o tratamento 3 de Paçoca de Munguba com adição de 5,65\% de manteiga nenhum dos atributos de cor aparente, aparência, textura aparente e granulometria aparentese assemelharam a paçoca ideal.

As Paçocas de Munguba (Pachira aquática Aubl.) em comparação com a amostra comercial elaborada com amendoim apresentaram diferença significativa com relação a suas cores aparente e aparências pelo teste de aceitação, tento médias de 
escores menores, porém em relação à preferência das amostras pelo teste de ordenação a única que houve diferença significativa com as demais amostras foi à amostra T2.

Conclui-se que é possível elaborar paçoca do Munguba (Pachira aquatica Aubl.), onde a amostra T1 de Paçoca de Munguba sem adição de manteiga obteve maior preferência quanto a seus atributos aparentes mostrando que a mesma tem características das quais pode ser facilmente introduzida no mercado, no entanto, são sugeridos para trabalhos futuros o melhoramento da textura e conduzir testes sensoriais de sabor, textura e odor em todas os tratamentos de Paçoca de Munguba, pois foi feito somente análises visuais devido a pandemia de COVID-19, com alteração possivelmente na formulação, além de realizar outras analises para caracterização com análises químicas e físicas.

\section{Referências}

Andrade-Cetto, A. \& Heinrich, M. (2005). Mexican plants with hypoglycaemic effect used in the treatment of diabetes. J Ethnopharmacol, 99 (3), $325-348$. 10.1016/j.jep.2005.04.019

AOAC. (1995). Association of Official Analytical Chemists. Official methods of analysis of the Association of the Analytical Chemists. 16th ed. Washington.

Cecchi, H. M. (2003). Fundamentos teóricos e práticos em análise de alimentos. (2a ed.), UNICAMP.

DEMO, P. (1995). Metodologia cientifica: em ciências sociais. (3a ed.), Atlas.

Dutcosky, S. D. (2007). Análise sensorial de alimentos. (2a ed.), Champagnat.

Guaglionani, D. G. (2009). Análise sensorial: Um estudo sobre procedimentos estatísticos e número mínimo de julgadores. Tese (Doutorado) - Curso de Pós Graduação em Alimentos e Nutrição, Universidade Estadual Paulista "Julio de Mesquita Filho", Araraquara. https://repositorio.unesp.br/bitstream/handle/11449/100945/guaglianoni_dg_dr_arafcf.pdf?sequence=1\&isAllowed=y.

Horwitz. W. (2000). Official Methods of Analysis of the Association of Official Analytical Chemists. (17a ed.), Gaithersburg, Maryland.

Instituto Nacional de Metrologia, Normalização e Qualidade. INMETRO. (2001). Produtos com certificação compulsória. <http://www.inmetro.gov.br/consumidor/produtos/amendoim.asp\#: :text=Segundo\%20a\%20Resolu\%C3\%A7\%C3\%A3o\%20n\%C2\%BA\%2012,quantidade\% 20de $\% 20$ cloreto $\% 20 \mathrm{de} \% 20$ s $\%$ C3\%B3dio\% 22.

Instituto Adolfo Lutz. (1985). Normas Analíticas do Instituto Adolfo Lutz: Métodos químicos e físicos para análise de alimentos. IMESP.

Jorge, N. \& Luzia, D. M. M. (2012). Caracterização do óleo das sementes de Pachira aquatica Aublet para aproveitamento alimentar. Acta Amazonica, Amazonia, 42 (1), 149-156. https://www.scielo.br/j/aa/a/fjHC7WdsZRR8vjYPkckRmzq/?format=pdf\&lang=pt.

Lima, J. R., Garruti, D. S., Araujo, I. M. S. \& Garcia, L. G. S. (2015). Relato de caso: caracterização físico-química e aceitabilidade de paçoca produzida com amêndoa de castanha-de-caju e sua comparação com produtos comerciais. Brazilian Journal Of Food Technology. 18 (4), 332-336. 10.1590/1981-6723.6615.

Lorenzi, H. (1992). Árvores Brasileiras: manual de identificação e cultivo de plantas arbóreas nativas do Brasil, Editora Plantarum Ltd. Nova Odessa.

Meilgaard, M.; Civille, G. V.; Carr, B. T. (1999). Sensory evaluation techniques. (3a ed.), CRC Press.

Newell, G. J.; MacFarlane, J. D. (1987). Expanded tables for multiple comparison procedures in the analysis of ranked data. Journal of Food Science, 52 (6), 1721-1725. 10.1111/j.1365-2621.1987.tb05913.x

Oetterer, M., M. A. B. Regitano-d'arce e M. H. F. Spoto. (2003). Fundamentos de Ciência e Tecnologia de Alimentos. Manole.

Peixoto, A. L. \& Escudeiro, A. (2002). Pachira aquática (Bombacaceae) na obra "história dos animais e árvores do Maranhão" de Frei Cristóvão de Lisboa. Rodriguésia. 53, 123-130. 10.1590/2175-78602002538205

Portal Action. (2021). Teste de Tukey (TSD - Tukey Significant Difference). http://www.portalaction.com.br/anova/31-teste-de-tukey.

Ribeiro, E. P. \& Seravalli E. A. G. (2004). Química de alimentos. Instituto Mauá de Tecnologia.

Ribeiro, V. A. (2006). Aproveitamento do resíduo do extrato de soja na elaboração de um produto tipo paçoca. Dissertação (Mestrado Ciência dos Alimentos)- Universidade Federal de Lavras, Lavras. http://repositorio.ufla.br/jspui/bitstream/1/3405/1/DISSERTA\%C3\%87\%C3\%83O_Aproveitam ento\%20do\% 20res\%C3\%ADduo\%20do\%20extrato\%20de\%20soja\%20na\%20elabora\%C3\%A7\%C3\%A3o\%20de\%20um\%20pr oduto\%20tipo \%20pa \% $3 \%$ A7oca.pdf.

Santos, G. G., Silva, M. R., Lacerda, D. B. C. L., Martins, D. M. O. Almeida, R. A. (2012). Aceitabilidade e qualidade físico-química de paçocas elaboradas com amêndoa de baru. Pesquisa Agropecuária Tropical, Goiânia, 42 (2), 159-165. https://www.scielo.br/j/pat/a/zVdD5cXRTSWWfd8tqJccjWh/?f ormat=pdf\&lang=pt.

Silva, B. L. A., Azevedo, C. C. \& Azevedo, F. L. A. A. (2015). Propriedades funcionais das proteínas de amêndoas da Munguba (Pachira aquatica Aubl.). Revista Brasileira de Fruticultura, Jaboticabal. 37 (1), 193-200. 10.1590/0100-2945-065/14 
Research, Society and Development, v. 10, n. 8, e9810816945, 2021

(CC BY 4.0) | ISSN 2525-3409 | DOI: http://dx.doi.org/10.33448/rsd-v10i8.16945

Silva, S. M. T. da, Morais, R. A., Costa, D. M. da, Teles, J. S., Rodrigues, R. M., Santos, C. C. A. do A., Nascimento, G. N. L. do, Cantanhede Filha, R. B., \& Pires, C. R. F. (2020). Caracterização físico-química, compostos bioativos e atividade antioxidante de amêndoas de Pachira aquatica Aublet. Research, Society and Development, 9(7), e535974391. 10.33448/rsd-v9i7.4391

Soares, W. P., Santiago, D. M., Campos, M. F. S., Carmo, C. A. \& Guerra, I. C. (2015). Análise sensorial de paçoca de cumbaru (Dipteryxalata Vog.) com adição de farinha de soja (Glycine Max L. Merril) e linhaça (Linum usitatíssimum L.) em diferentes porcentuais. Trabalho apresentado em Anais do Simpósio Latino Americano de Ciências de Alimentos. Disponível: http://cea.blv.ifmt.edu.br/media/filer_public/9d/e6/9de624ba-8156-41cd96d7ecb41e66644b/analise_sensorial_de_pacoca_de_cumbaru_dipteryxalata_vog_com_adicao_farinha_de_soja_glycine_max_1_merril_e_linhaca_linum_usit atissimum_1_em_diferentes_percentuais.pdf.

Souza, Manoel. (2017). Análise sensorial de produto elaborado a partir da farinha de munguba (Pachira aquatica Aubl.). In: VI - Congresso Latino-Americano, Brasilia. Brasilia: Agroecologia 2017. (13). http://cadernos.aba-agroecologia.org.br/index.php/cadernos/article/view/831/489.

Wang, S. H., Cabral, L. C. \& Borges, G. G. (1999). Utilização do resíduo do leite de soja na elaboração de paçoca. Pesquisa Agropecuária Brasileira, Brasília. 34 (7), 1305-1311. 10.1590/S0100-204X1999000700024 